\title{
A UTILIZAÇÃo DE ETANOL EM CÉLULA A COMBUSTÍVEL DE ÓXIDO SÓLIDO
}

\author{
Raigenis da Paz Fiuza, Marcos Aurélio da Silva, Luiz Antônio Magalhães Pontes, Leonardo Sena Gomes Teixeira e Jaime \\ Soares Boaventura* \\ Escola Politécnica, Universidade Federal da Bahia, Rua Prof. Aristides Novis, 2, 40210-630 Salvador - BA, Brasil
}

Recebido em 31/8/11; aceito em 23/2/12; publicado na web em 15/6/12

\begin{abstract}
THE USE OF ETHANOL IN SOLID OXIDE FUEL CELLS. This work reports a review on the status and technical feasibility of the application of ethanol as fuel for Solid Oxide Fuel Cells (SOFC), presenting both external reform and cell with direct utilization of ethanol. Based on this survey, both experimental results and mathematical modeling indicated the technical feasibility of power generation by ethanol SOFC, with cell units producing $450 \mathrm{~mW} / \mathrm{cm}^{2}$, sufficient for scale up to large stationary plants. The quantitative assessments in the literature show this field to be promising for researchers and private sector investment as well being a strategic technology for government policy in the short and long term.
\end{abstract}

Keywords: fuel cell; SOFC; ethanol.

\section{INTRODUÇÃO}

Governos, empresas privadas e instituições de pesquisa e desenvolvimento, mundialmente, vêm buscando desenvolver e viabilizar, tanto técnica como comercialmente, fontes alternativas de geração de energia, a fim de garantir sua oferta e a sustentabilidade ambiental para as próximas décadas. ${ }^{1-4}$ No Brasil, várias medidas têm sido tomadas com o objetivo de reduzir o consumo de combustíveis fósseis, como é o caso do programas brasileiros de biocombustíveis, através do uso do biodiesel ${ }^{5-8}$ e do bioetanol. ${ }^{9}$ Ambos contribuem para a redução das emissões de gases de efeito estufa e, ao mesmo tempo, da dependência de derivados de petróleo. ${ }^{10}$ Medidas similares têm sido observadas em outros países, visando principalmente a diversificação de sua matriz energética. ${ }^{1,11}$ A Comunidade Europeia, por exemplo, tem desenvolvido uma forte campanha para o uso da energia eólica e produção de biodiesel:12-14 nos EUA verifica-se um estímulo à produção de bioetanol, ${ }^{15}$ dentre outras iniciativas importantes. Neste contexto, é que se insere a tecnologia baseada no hidrogênio e as células a combustível. Muitos países têm feito vultosos investimentos no desenvolvimento das tecnologias de células a combustível, tais como o centro de Forschungszentrum Jülich GmbH (Jülich Research Centre), na Alemanha, e o Departamento de Energia (DoE) dos Estados Unidos, além de iniciativas importantes em muitos outros países. ${ }^{16}$ No Brasil, as células a combustível demonstraram tal importância estratégica para a matriz de energia nacional que justificou a criação do Programa de Células a Combustível - PROCAC. O PROCAC foi criado em 2004, dentro das ações realizadas no âmbito da economia do hidrogênio pelo Ministério da Ciência e Tecnologia. Este programa teve como objetivo estimular o desenvolvimento de tecnologia nacional de células a combustível e formação de recursos humanos na área. ${ }^{17}$

As células a combustível são dispositivos eficientes para a conversão eletroquímica de um combustível em energia elétrica; ${ }^{18,19}$ podendo substituir alguns dos geradores convencionais de produção de energia. ${ }^{20} \mathrm{Na}$ célula a combustível, a energia química de um combustível é convertida diretamente em energia elétrica, sem os limites termodinâmicos das máquinas térmicas, ${ }^{20}$ podendo atingir eficiência em torno $80 \% .{ }^{19}$ Dentre os diversos tipos de células, a célula a combustível de óxido sólido (PACOS), ou como é mais

*e-mail: bventura@ufba.br conhecida na literatura internacional Solid Oxide Fuel Cell - SOFC, tem ganhado amplo destaque. Devido à elevada temperatura de operação $\left(500-1000{ }^{\circ} \mathrm{C}\right)$, a SOFC oferece grande flexibilidade no uso de combustíveis, podendo tanto usar hidrogênio quanto gás natural e derivados de biomassa, ${ }^{21}$ como o bioetanol. ${ }^{22}$ No caso do uso de gás natural ou bioetanol, pode-se fazer tanto o processo de reforma prévia do combustível (transformação prévia do combustível em hidrogênio) como alimentá-lo diretamente na célula. O uso de etanol em SOFCs é muito relevante para o Brasil, em função do programa nacional de bioetanol, com uma rede de distribuição bem consolidada. Considerando-se os sérios riscos na logística de armazenamento e transporte do hidrogênio, ${ }^{23-25}$ o uso do bioetanol representaria uma alternativa importante rumo à viabilização técnica e econômica das SOFCs, além de ser uma estratégia adequada para a geração de energia aliada à sustentabilidade. ${ }^{26}$

$\mathrm{O}$ uso de etanol em SOFC associa duas vantagens principais: a produção de energia elétrica com elevada eficiência da SOFC e a origem renovável e sustentável do etanol. Estas vantagens podem ser concretizadas, pois a viabilidade técnica na utilização de etanol em SOFC vem sendo comprovada em vários estudos experimentais, ${ }^{27-30}$ assim como por modelos matemáticos e termodinâmicos. ${ }^{31-33}$ Entretanto, ainda há alguns empecilhos tecnológicos para a aplicação prática da SOFC. O principal empecilho é a elevada deposição de carbono promovida pelo eletrocatalisador anódico, ${ }^{34}$ seja a célula alimentada com etanol puro ou misturas de etanol e água, quando alimentado diretamente no anodo da célula. Outro problema é a formação de carbono durante produção de hidrogênio para células que usem reformador externo de etanol. ${ }^{35}$

O objetivo deste trabalho foi identificar e discutir os aspectos técnicos relacionados à utilização de etanol como combustível em células a combustível de óxido sólido. Para isso, foram destacados os principais estudos teóricos e experimentais, as principais configurações das células e as reações de transformação do etanol para alimentá-las.

\section{TIPOS DE CONFIGURAÇÕES DE SOFC}

Os tipos de configurações de SOFC geralmente se relacionam à alimentação de combustível. A SOFC pode operar em três diferentes tipos de configurações: operação com reformador externo; reformador interno indireto (IIR-SOFC) e reformador interno direto (DIR-SOFC). 
Devido à operação em altas temperaturas das SOFCs (500-1000 ${ }^{\circ} \mathrm{C}$ ), o etanol pode ser reformado a hidrogênio na própria célula. Esta técnica é conhecida como SOFC com reforma interna (IR-SOFC), onde se aproveita o calor da operação das células para reformar o combustível, apresentando ganho global de eficiência. ${ }^{36,37}$ A IR-SOFC pode ser dividida em dois tipos: reforma interna indireta (IIR- SOFC) e reforma interna direta (DIR-SOFC). No primeiro caso (IIR-SOFC), o combustível é alimentado na seção de reforma que está fisicamente separada dos dispositivos da célula, estando localizado próximo ao anodo da célula a combustível, conforme mostrado na Figura 1. Neste tipo de configuração, o reformador de combustível e a célula são mantidos aproximadamente na mesma temperatura, envoltos por um caixa isolante. Na Figura 1 é mostrado um esquema de uma SOFC com reformador interno de etanol exclusivo para a célula, em que a mistura de etanol e água (ou etanol puro) é transformada em hidrogênio em um reformador catalítico aquecido a temperaturas superiores a $500{ }^{\circ} \mathrm{C}$. O gás produzido, rico em hidrogênio, alimenta a célula; se este gás for purificado em etapas posteriores, o desempenho da célula poderá ser significativamente melhorado, principalmente, porque eliminará a formação de carbono no anodo. A purificação do gás rico em hidrogênio pode ser conduzida por sistemas de separação física (membranas seletivas) $)^{38,39}$ ou reação química (principalmente para reformar hidrocarbonetos/oxigenados residuais, reduzindo-se o teor de $\mathrm{CO}$ e assim evitando-se a reação de Boudoart no sentido de formação de carbono). ${ }^{40}$

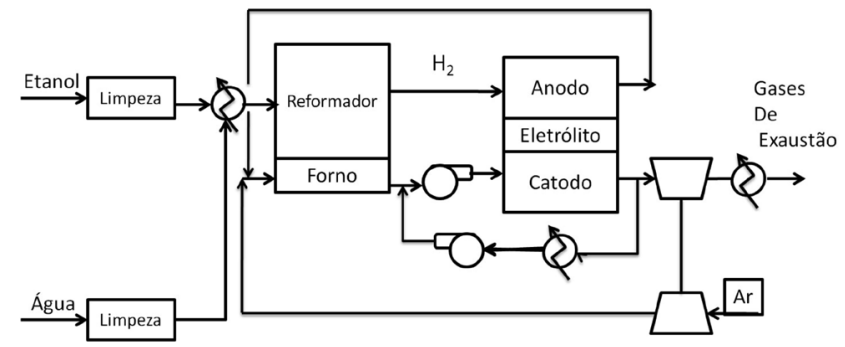

Figura 1. SOFC a etanol com reforma interna indireta. Nesta configuração o combustivel é inicialmente reformado, produzindo hidrogênio que alimentará à célula

Na Figura 2 é mostrado um esquema de uma SOFC alimentada com etanol diretamente no anodo (DIR-SOFC), sem o uso de reforma prévia. Neste tipo de configuração, a mistura de água e etanol (ou etanol puro) é alimentada diretamente no anodo da célula na forma de vapor. ${ }^{41} \mathrm{~A}$ célula opera geralmente a temperaturas superiores a $500{ }^{\circ} \mathrm{C}$. A principal vantagem na operação da DIR-SOFC é que o hidrogênio produzido a partir da reação de reforma do etanol é continuamente consumido durante a oxidação do hidrogênio para geração de energia elétrica, facilitando assim a reforma do combustível, de acordo com o princípio de Le Châtelier. Contudo, a alimentação direta de etanol leva à formação de carbono no anodo, o que provoca sua rápida perda de atividade catalítica e, consequentemente, a redução do tempo de vida útil da célula, ${ }^{32,42}$ ou até mesmo a destruição física do anodo. Portanto, é importante que o eletrocatalisador anódico seja avaliado quanto à conversão de etanol, ao rendimento de hidrogênio e distribuição de demais subprodutos, ${ }^{43-47}$ regenerabilidade, ${ }^{48}$ formação de carbono e outros aspectos como estabilidade, natureza e ação do suporte, ${ }^{49-52}$ antes de ser utilizado como anodo (eletrocatalisador) de uma SOFC. ${ }^{53}$

Além das configurações DIR-SOFC e IIR-SOFC, é possível que a SOFC opere com um reformador completamente separado da célula, a qual é chamada de SOFC com reformador externo (ER-SOFC). Neste tipo de configuração, não há conexão direta entre os gases de efluxo do reformador e a célula, assim o gás rico em hidrogênio pode passar por processos de purificação antes de alimentar a célula,

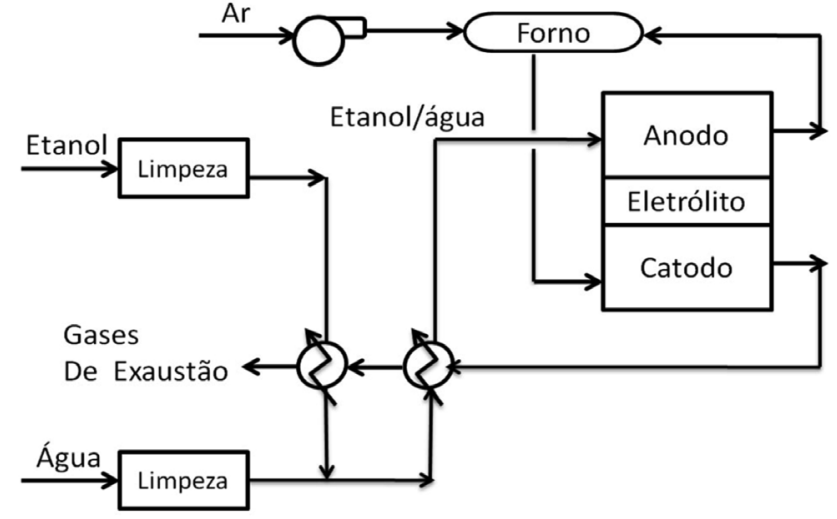

Figura 2. SOFC com reforma direta no anodo. Nesta configuração o combustivel é alimentado diretamente no anodo da pilha

com a vantagem de poder ser armazenado e transportado..$^{40,54,55} \mathrm{~A}$ ER-SOFC não possui problemas de formação de carbono no anodo, pois é alimentada com hidrogênio puro.

Embora haja extensivos estudos em andamento, tanto para a configuração DIR-SOFC quanto para a IIR-SOFC, observa-se que o menor tamanho e peso, a facilidade de transporte e a simplicidade do equipamento fazem com que a configuração DIR-SOFC seja a mais promissora para aplicações industriais de pequeno a médio porte, especialmente aquelas que exijam algum tipo de portabilidade ou locomoção. A configuração ER-SOFC é mais apropriada para grandes unidades geradoras de energia elétrica, concebidas como instalações fixas e permanentes.

\section{APLICAÇÕES DAS SOFCs E ESTIMATIVAS DE CUSTOS}

A maioria dos estudos aponta que as SOFCs serão destinadas ao mercado de geração distribuída de energia, ou seja, geração de energia em unidades de pequeno e médio porte no local de consumo (5 a $200 \mathrm{~kW}) .{ }^{56}$ Os sistemas estacionários também podem se enquadrar na definição de "geração distribuída de energia", ${ }^{57-59}$ quando os investimentos em manutenção das linhas de transmissão elétrica e subestações são drasticamente reduzidos; estes custos são comuns aos sistemas tradicionais de geração de energia, a exemplo dos geradores hidráulicos e térmicos, como esquematizado na Figura 3. A geração distribuída também reduz significativamente as perdas de energia em geração, subestação e transmissão; entretanto, demandam equipamentos robustos e de elevada eficiência, confiabilidade, durabilidade e, quando necessário, a possibilidade de monitoramento remoto. ${ }^{59}$ Principalmente em unidades remotas, a utilização de etanol em SOFCs pode ser mais segura em relação a outros combustíveis, pela facilidade e segurança de transporte e estocagem do etanol, além da disponibilidade em relação ao hidrogênio.

Os preços das SOFCs são competitivos em vários nichos de mercado, quando alcançam custo de fabricação da ordem de

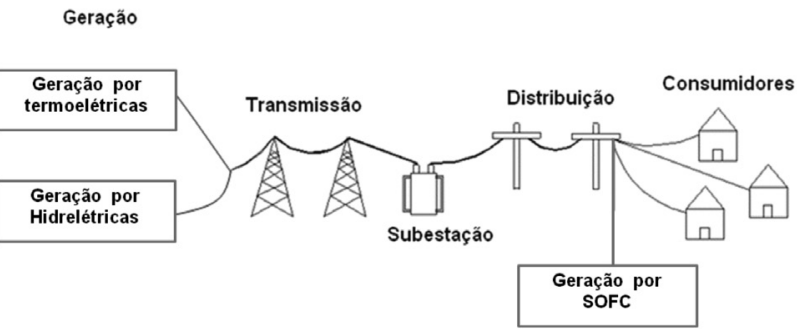

Figura 3. Ilustração de sistemas tradicionais de geração de energia e a inserção de SOFCs na geração distribuída 
US\$ 1.400 a 1.800/kW. Valores desta ordem vêm sendo projetados pelo Departamento de Energia (DoE) dos Estados Unidos, no maior e mais bem financiado programa de desenvolvimento de SOFCs do mundo. ${ }^{59}$ Estes estudos indicam que a diminuição do custo das SOFC, com reformador externo ou interno, decorrerá principalmente do aumento de eficiência e diminuição de custo do reformador de combustível.

Atualmente, os dados disponíveis de custo e eficiência de produção de hidrogênio a partir de diferentes fontes dependem do tamanho da unidade produtora. A produção via reforma a vapor do gás natural pode variar de US\$2,11 até US\$ 3,68/kg para plantas de grande e pequeno porte, respectivamente; em ambos os casos a eficiência fica em torno de $70 \%$. Por outro lado, se o hidrogênio for produzido a partir da eletrólise da água, o seu custo pode atingir US\$ 7,36/kg com eficiência de $27 \%$. Os estudos de prototipagem, dimensionamento e avaliação econômica das unidades de SOFC indicam que o gerador de hidrogênio pode representar até $50 \%$ do valor total da célula. ${ }^{55}$

\section{AVALIAÇÕES TEÓRICAS DA UTILIZAÇÃO DO ETANOL EM SOFC}

Uma série de estudos de simulação tem buscado compreender os diversos aspectos da SOFC alimentada com etanol, especialmente fornecendo diretrizes para predizer o efeito das condições operacionais sobre o desempenho da célula. ${ }^{31-33,60,61}$ Estes estudos teóricos também são necessários para a compreensão das complexas características elétricas de uma célula a combustível; efeitos estes relacionados às reações químicas que ocorrem em cada componente, ao tipo de combustível e aos processos de transporte de massa e calor. As simulações resultam em previsões mais precisas do comportamento de célula a combustível, levando a uma concepção mais aproximada das suas condições ideais de operação.

Arpornwichanop et al..$^{31}$ avaliaram o desempenho de uma SOFC suportada no anodo (Ni/YSZ - 35\% de níquel metálico sobre $\left.\left.\left[\left(\mathrm{Zr}_{2} \mathrm{O}\right)_{0,9}\left(\mathrm{Y}_{2} \mathrm{O}_{3}\right)_{0,1}\right)\right]\right)$ com reforma direta de etanol, usando um modelo unidimensional acoplado a um modelo eletroquímico. Foram considerados como parâmetros a espessura do anodo, temperatura, pressão e grau de pré-reforma de etanol. Os autores concluíram que anodos menos espessos $(250 \mathrm{~nm})$ influenciam negativamente na eficiência da célula, devido à diminuição da área ativa de catalisador e, assim, na extensão de reação de oxidação do etanol. Os anodos mais espessos $(1000 \mathrm{~nm})$ dificultam o transporte de reagentes para a interface ânodo-eletrólito, resultando em aumento do sobrepotencial e consequente diminuição da eficiência da célula. Em consequência, a espessura do anodo deve ser cuidadosamente ajustada para otimizar o desempenho da SOFC. Além disto, os autores concluíram, em relação à utilização de etanol na célula e a razão água/etanol (variada de 5 a 11), que elevados valores da razão água/etanol diminuem a concentração de $\mathrm{H}_{2}$ no gás alimentado à célula e acarretam diminuição da taxa de reação eletroquímica, levando à redução da densidade de corrente gerada pela célula. Assim, a eficiência da célula e a utilização de combustíveis são melhoradas para menores razões água/etanol, devido à maior concentração de combustível presente (etanol-hidrogênio). O aumento da temperatura de operação pode também melhorar o desempenho da célula, desde que promova maior taxa de reação eletroquímica e maior consumo de combustível. Assim, a densidade de corrente gerada será maior e, consequentemente, a eficiência e a economia de combustível serão incrementadas. Entretanto, o aumento de temperatura do sistema afeta fortemente a contribuição individual de perdas de tensão e sobrepotencial. Adicionalmente, verifica-se que a perda ôhmica é também uma função linear da densidade de corrente; portanto, seu valor pode aumentar significativamente quando a densidade de corrente é gerada em temperaturas mais elevadas.

Artega-Perez et al. ${ }^{33}$ estudaram uma SOFC integrada com um sistema de reforma a vapor de etanol, usando um catalisador convencional de reforma $\left(\mathrm{Ni} / \mathrm{Al}_{2} \mathrm{O}_{3}\right)$. A eficiência da célula e do sistema de reforma foram estudadas sob diferentes condições: temperatura (500 $\left.<\mathrm{T}<600^{\circ} \mathrm{C}\right)$, razão molar água/etanol $(3<\mathrm{RAE}<6)$ e coeficiente de utilização do combustível $(0<\mathrm{CUC}<90 \%)$. O sistema mostrou-se energeticamente autossustentável quando a SOFC operou nas seguintes condições: coeficiente de utilização do combustível, $80 \%$; temperatura da reação de reforma a vapor do etanol, $550{ }^{\circ} \mathrm{C}$; e razão molar água/etanol, 1/1,5.

Tsiakaras e Demin fizeram uma análise termodinâmica detalhada a fim de fornecer informações sobre a utilização do etanol como combustível alternativo em células a combustível de óxido sólido, usando diferentes oxidantes durante a etapa de reforma do combustível, conduzida fora da célula. ${ }^{60}$ Foram consideradas SOFCs alimentadas com os produtos do equilíbrio termodinâmico de várias reações do etanol: reforma a vapor; reforma com $\mathrm{CO}_{2}$ e oxidação parcial com ar. Em todos os casos foi utilizado o catalisador tradicional de $\mathrm{Ni} /$ $\mathrm{Al}_{2} \mathrm{O}_{3}$. A reforma a vapor foi o método de transformação de etanol mais promissor do ponto de vista termodinâmico. Verificou-se que a eficiência teórica obtida no sistema SOFC utilizando a reforma com vapor de etanol variou entre 83,9 e 93,8\% nas condições examinadas. Para a célula alimentada com etanol reformado com $\mathrm{CO}_{2}$, a eficiência ficou entre 83,6 e $89,9 \%$, na faixa de temperatura de 677 a $827^{\circ} \mathrm{C}$. Para o etanol reformado a partir da oxidação parcial com ar, a eficiência máxima foi $73,5 \%$ a $787^{\circ} \mathrm{C}$.

Cimenti et al.$^{32}$ fizeram uma análise termodinâmica de uma SOFC operando com metanol e etanol com utilização direta do combustível no anodo (Ni/YSZ), empregando a reforma a vapor ou a oxidação parcial. Foram determinadas a composição de equilíbrio, a deposição de carbono e a força eletromotriz da SOFC. Foi também calculada a quantidade mínima de $\mathrm{H}_{2} \mathrm{O}$ e $\mathrm{CO}_{2}$, tanto na reforma direta como indireta, para evitar a formação de carbono. Os resultados dos cálculos de equilíbrio mostraram que $\mathrm{H}_{2}$ e $\mathrm{CO}$ são os principais produtos da pirólise do metanol. A presença de carbono foi prevista na faixa de temperatura considerada $\left(800\right.$ a $\left.1000^{\circ} \mathrm{C}\right)$, mas sua concentração no equilíbrio diminuiu significativamente com o aumento da temperatura. Nessas temperaturas, a constante de equilíbrio para a reação $\mathrm{CH}_{3} \mathrm{OH}$ $\rightarrow 2 \mathrm{H}_{2}+\mathrm{CO}$ é superior à de qualquer outra via de decomposição do metanol, de tal forma que só esta reação deve ser considerada para estimar a composição de equilíbrio. A presença de pequenas quantidades de $\mathrm{H}_{2} \mathrm{O}$ (líquido) no metanol (por exemplo, 2,6\% em volume de uma SOFC operando a $800{ }^{\circ} \mathrm{C}$ ) deve ser suficiente para suprimir a formação de carbono em equilíbrio. Para o metanol, foi identificado o valor mínimo da utilização do combustível para o qual nenhum carbono estaria presente no meio: $2,1 \%$, em torno de $800{ }^{\circ} \mathrm{C}$. Para a reforma a vapor do etanol, grandes quantidades de $\mathrm{H}_{2} \mathrm{O}$ (em torno de três mols por mol de etanol) devem ser adicionadas ao etanol puro a fim de evitar a formação de carbono (por exemplo, 25,7\% em volume para a operação da SOFC a $800^{\circ} \mathrm{C}$ ). Por fim, o aproveitamento mínimo do combustível de uma SOFC alimentada com etanol para operar fora da região de formação de carbono foi de $19,5 \%$ a $800{ }^{\circ} \mathrm{C}$.

Os estudos teóricos apresentados revelam que a aplicação de etanol em SOFCs é viável, tanto para DIR-SOFC como para IIRSOFC. Esses estudos apontam as melhores condições para a operação da célula com bom desempenho. Os principais parâmetros a serem controlados são temperatura de operação da célula, taxa de conversão do etanol, formação de carbono e pressão parcial do etanol na alimentação. Todos estes parâmetros estão direta ou indiretamente relacionados com o eletrocatalisador anódico, ou seja, dependem da natureza do metal ativo do anodo e seu suporte. 


\section{OPERAÇÃO E DESEMPENHO DE SOFC ALIMENTADA COM ETANOL}

A alimentação de SOFCs com etanol é um campo de pesquisa importante dentro de um universo maior, que é o desenvolvimento de SOFCs. A proposta de uso de etanol nas SOFCs é relativamente recente e conta com um grande número de trabalhos científicos na área. Os resultados das pesquisas vêm se tornando, a cada dia, mais consistentes e já apontam o etanol como um combustível promissor.

Silva et al., em um estudo pioneiro no Brasil, prepararam SOFCs unitárias com anodos formados por eletrocatalisadores à base de níquel e cobalto suportados em YSZ $\left[\left(\mathrm{Zr}_{2} \mathrm{O}\right)_{0,9}\left(\mathrm{Y}_{2} \mathrm{O}_{3}\right)_{0,1}\right]$, LSM $\left(\mathrm{La}_{0,50} \mathrm{Sr}_{0,50} \mathrm{MnO}_{3}\right)$ como catodo e YSZ como eletrólito, sendo estas alimentadas com etanol. ${ }^{22,28}$ Quando a célula foi alimentada com etanol, obteve-se tensão em circuito aberto de $0,85 \mathrm{~V}$, a 900 ${ }^{\circ} \mathrm{C}$. A potência máxima obtida foi relativamente baixa, em torno de $5 \mathrm{~mW} / \mathrm{cm}^{2}$ a $950{ }^{\circ} \mathrm{C}$, devido possivelmente à elevada espessura do eletrólito $(0,5 \mathrm{~mm})$. Apesar dos baixos valores de potência, foi uma experiência pioneira no desenvolvimento de SOFCs alimentadas a etanol no Brasil e estimulou outros estudos..$^{53,62,63}$

Venâncio et al. ${ }^{41}$ desenvolveram eletrodos à base de céria e cobre depositados sobre YSZ, para oxidação direta de etanol em células do tipo SOFC. A célula foi construída com YSZ, como eletrólito, e $\mathrm{La}_{0,8} \mathrm{Sr}_{0,2} \mathrm{MnO}$, como catodo. Nenhuma degradação de desempenho foi observada após $200 \mathrm{~h}$ de operação da SOFC. Após a operação, o anodo apresentou-se totalmente isento de carbono, sugerindo que um material à base de céria e cobre é um anodo com excelente potencial para a oxidação direta de etanol em SOFC. A célula atingiu 250 e $170 \mathrm{~mW} / \mathrm{cm}^{2}$ operando a $900{ }^{\circ} \mathrm{C}$ quando alimentada com hidrogênio e etanol, respectivamente. Entretanto, esta temperatura ainda é excessivamente elevada para a aplicação comercial de SOFC de média e pequena potência.

Ye et al. ${ }^{29}$ estudaram um anodo fabricado em dupla camada: $\mathrm{Ni}-\mathrm{ScSZ}$ (níquel suportado em zircônia estabilizada com escândia) como anodo funcional e suporte estrutural das células; $\mathrm{Cu}-\mathrm{CeO}_{2}-\mathrm{YSZ}$ constituiu o segundo leito do anodo. A densidade de potência máxima da célula unitária atingiu 604 e $408 \mathrm{~mW} / \mathrm{cm}^{2}$ com hidrogênio e etanol, respectivamente, quando operando a $800{ }^{\circ} \mathrm{C}$. A estrutura do anodo também mostrou boa estabilidade, sem degradação aparente após 50 $\mathrm{h}$ de operação, utilizando tanto etanol quanto hidrocarbonetos como combustível. Este é um resultado experimental muito animador para o campo das pesquisas nesta área. Entretanto, o caminho experimental seguido pelos autores, considerando suas inerentes dificuldades, deve ser exaustivamente aprofundado, a fim de aperfeiçoá-lo e torná-lo cada vez mais reprodutivo e repetitivo, atendendo às demandas comerciais de estabilidade e confiabilidade.

Cimenti e Hill ${ }^{64}$ investigaram a utilização direta de metanol e etanol em SOFC sobre anodos à base de $\mathrm{Cu}-\mathrm{Co}(\mathrm{Ru}) / \mathrm{Zr}_{0,35} \mathrm{Ce}_{0,65} \mathrm{O}_{2}$ preparados por impregnação. As células apresentaram desempenhos e estabilidade semelhantes com $\mathrm{H}_{2}$ ou metanol. Com o etanol, o desempenho variou de acordo com tempo de uso da célula, isto é, a densidade de potência aumentou inicialmente e depois decresceu exponencialmente com o tempo de uso. Este comportamento, segundo os autores, foi provavelmente uma consequência da deposição de carbono que, inicialmente, aumentava a condutividade eletrônica na camada funcional do anodo e, posteriormente, bloqueava sítios ativos do eletrocatalisador. A potência máxima obtida, tanto para etanol como metanol, foi aproximadamente $450 \mathrm{~mW} / \mathrm{cm}^{2}$ a $800{ }^{\circ} \mathrm{C}$.

Lanzini et al. ${ }^{65}$ estudaram a flexibilidade de utilização de combustível, bem como a viabilidade do uso do etanol em um gerador SOFC de $5 \mathrm{~kW}$ projetado para gás natural (GN). As eficiências elétrica e global, alcançadas em condições nominais de operação, mostraram que o etanol mantém o bom desempenho do gerador: $45 \%$ de eficiência obtida com etanol e $48 \%$ alcançado com GN.

O estágio de desenvolvimento de SOFCs alimentadas com hidrogênio já impulsiona projetos de construção de células de maior porte, ${ }^{66,67}$ com potências que variam de 5 a $200 \mathrm{~kW}$, a exemplo dos projetos da Fuel Cell Technologies e da Siemens Westinghouse. ${ }^{17}$ Parte significativa do aprendizado técnico utilizado para a construção destas células pode ser empregado para o desenvolvimento de SOFCs alimentadas a etanol, respeitando-se as particularidades das propriedades físicas do combustível e exigências técnicas dos materiais, principalmente características catalíticas do anodo, que podem ser obtidas dos estudos de reforma de etanol.

Os resultados das investigações do uso de etanol em SOFC apontam para resultados comparáveis com células alimentadas com hidrogênio puro, em condições similares de operação. Entretanto, o etanol apresenta vantagens do ponto de vista da segurança, facilidade de transporte e armazenamento, o que ajuda a torná-lo bastante competitivo em relação ao hidrogênio.

\section{REAÇÃO QUÍMICA DO ETANOL NA SOFC}

\section{Reforma externa de etanol}

As SOFCs alimentadas a etanol com reformador externo contêm um dispositivo auxiliar para converter o etanol em hidrogênio - um reformador catalítico. Neste reformador é possível produzir um gás rico em hidrogênio por diferentes reações: reforma a vapor, reforma autotérmica (reforma oxidativa a vapor) e oxidação parcial, conforme as Equações 1 a 3:68

$\mathrm{CH}_{3} \mathrm{CH}_{2} \mathrm{OH}+3 \mathrm{H}_{2} \mathrm{O} \rightarrow 2 \mathrm{CO}_{2}+6 \mathrm{H}_{2}$ reforma a vapor do etanol (1) $\mathrm{CH}_{3} \mathrm{CH}_{2} \mathrm{OH}+2 \mathrm{H}_{2} \mathrm{O}+1 / 2 \mathrm{O}_{2} \rightarrow 2 \mathrm{CO}_{2}+5 \mathrm{H}_{2}$ reforma autotérmica (2) $\mathrm{CH}_{3} \mathrm{CH}_{2} \mathrm{OH}+1 / 2 \mathrm{O}_{2} \rightarrow 2 \mathrm{CO}+3 \mathrm{H}_{2} \quad$ oxidação parcial (3)

Neste tipo de célula, os componentes - anodo, eletrólito e catodo - podem ter composições iguais às células alimentadas diretamente com hidrogênio puro, particularmente, nos seguintes casos: se o efluxo do reformador passar por processo de purificação; ou se o catalisador usado no reformador for muito seletivo para a produção de hidrogênio. Um dos processos típicos de enriquecimento da corrente de hidrogênio do reformador é remoção do CO com água, pela reação de shift (Equação 4): ${ }^{69}$

$$
\mathrm{CO}+\mathrm{H}_{2} \mathrm{O} \rightarrow \mathrm{CO}_{2}+\mathrm{H}_{2}
$$

Os catalisadores industriais ou usados em pesquisa são geralmente baseados em metais como $\mathrm{Ni}, \mathrm{Fe}, \mathrm{Co}, \mathrm{Cu}$, depositados em uma variedade de suportes. ${ }^{70-73}$ Alternativamente, a reação de reforma do etanol pode ser conduzida em presença de metais nobres, como $\mathrm{Rh}, \mathrm{Ru}, \mathrm{Pd}$ e Pt. ${ }^{50,74-77}$ Estes catalisadores podem ser preparados por métodos diferentes, tais como impregnação, precursores poliméricos (método Pechini), sol-gel, combustão, coprecipitação, entre outros. ${ }^{72,78}$

A reforma a vapor de etanol (RVE) é uma reação amplamente estudada, recebendo grande atenção dos pesquisadores, ${ }^{55,79}$ devido ao elevado potencial de produção de hidrogênio (três mols de $\mathrm{H}_{2}$ por mol de etanol). É um processo químico muito complexo, com um mecanismo de reação envolvendo várias etapas catalisadas..$^{80-84}$ Muitas outras reações podem ocorrer simultânea ou sucessivamente, tais como desidratação, decomposição, desidrogenação, formação de carbono, entre outras. ${ }^{68}$ Estes estudos mostram que na RVE o caminho da reação é provavelmente dependente do catalisador empregado e das condições de reação.

Na RVE, as atividades dos catalisadores diminuem com o tempo de reação, principalmente pela deposição de materiais carbonáceos 
Tabela 1. Alguns catalisadores utilizados para a reforma a vapor de etanol: composição, relação água/etanol, rendimento a hidrogênio e estimativa de formação de carbono (*GDC $-\mathrm{Gd}_{0,1} \mathrm{Ce}_{0,9} \mathrm{O}_{2}$ )

\begin{tabular}{|c|c|c|c|c|c|}
\hline Catalisador & $\%$ Metal & Etanol/ $\mathrm{H}_{2} \mathrm{O}$ & Rendimento, $\mathrm{H}_{2}(\%)^{\mathrm{a}}$ & $\begin{array}{l}\text { Carbono total formado } \\
\text { (monocamada })^{\mathrm{b}}\end{array}$ & Ref. \\
\hline \multirow[t]{3}{*}{$\mathrm{Ni} / \mathrm{CeO}_{2}$} & 5,0 & $1 / 3$ & 82,5 & 1,08 & 94 \\
\hline & & $1 / 2$ & 76,4 & 1,17 & \\
\hline & & $1 / 1$ & 65,5 & 1,26 & \\
\hline \multirow[t]{3}{*}{$\mathrm{Ni} / \mathrm{Al}_{2} \mathrm{O}_{3}$} & 5,0 & $1 / 3$ & 57,2 & 4,54 & 94 \\
\hline & & $1 / 2$ & 54,2 & 4,78 & \\
\hline & & $1 / 1$ & 53,1 & 4,79 & \\
\hline $\mathrm{Ni} 0 \mathrm{ZnAl}{ }^{\mathrm{f}}$ & $\approx 50^{\mathrm{e}}$ & $1 / 3$ & $\approx 60^{\mathrm{e}}$ & --- & 93 \\
\hline $\mathrm{Ni} 50 \mathrm{MgAl}{ }^{\mathrm{f}}$ & $\approx 50^{\mathrm{e}}$ & $1 / 3$ & $\approx 60^{\mathrm{e}}$ & ---- & \\
\hline $\mathrm{Cu}-\mathrm{Ni} / \mathrm{SiO}_{2}$ & $\begin{array}{l}1,5 \% \mathrm{Cu} \\
13,5 \% \mathrm{Ni}\end{array}$ & 0,27 & $50\left(650^{\circ} \mathrm{C}\right)$ & $\begin{array}{l}50 \% \text { da massa de catalisador em } \\
3 \mathrm{~h} \mathrm{a} 650{ }^{\circ} \mathrm{C}\end{array}$ & 70 \\
\hline $\mathrm{Rh} / \mathrm{Al}_{2} \mathrm{O}_{3}$ & 5,0 & $0,12 / 1^{\mathrm{c}}$ & $91,6^{c}$ & $0,28^{\mathrm{cd}}$ & 92 \\
\hline YSZ-GDC/FeNi & $\begin{array}{c}5 \% \mathrm{Ni} \\
30 \% \mathrm{Fe}\end{array}$ & $1 / 3$ & $45\left(800^{\circ} \mathrm{C}\right)$ & $\begin{array}{l}9,5 \% \text { da massa de catalisador em } \\
3 \text { h a } 650{ }^{\circ} \mathrm{C}\end{array}$ & 34 \\
\hline
\end{tabular}

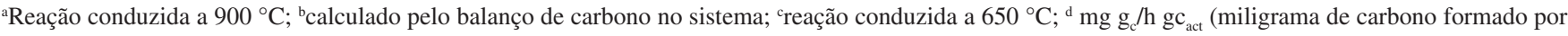
grama de catalisador por hora); ${ }^{\mathrm{e} a c i m a}$ de $750{ }^{\circ} \mathrm{C}$; f derivados de hidrotalcitas.

sobre a superfície do catalisador. Geralmente essa desativação é acompanhada de forte aumento na produção de acetaldeído. ${ }^{85}$ Este é um problema da maioria dos catalisadores à base de metais suportados em óxidos de natureza ácida, como zircônia, céria ou alumina. A adição de espécies alcalinas ao catalisador, para neutralizar sítios ácidos, representa uma das opções possíveis para melhorar o rendimento a hidrogênio na reforma a vapor de etanol. ${ }^{69,86-88} \mathrm{~A}$ neutralização de sítios ácido pode inibir a formação de produtos provenientes de reações de desidratação, prováveis responsáveis pela produção de carbono. A adição de espécies de caráter básico ao catalisador, visando minimizar a formação de carbono, tem exibido sucesso, principalmente quanto ao aumento da estabilidade do catalisador. ${ }^{42,46,86,89-91}$

Na Tabela 1 são sumarizados alguns catalisadores típicos para a reforma de etanol. Verifica-se que os catalisadores à base de níquel têm rendimento a hidrogênio relacionado com a razão molar etanol/água e com o suporte utilizado. ${ }^{87}$ Observa-se ainda que a alumina é mais ativa na formação de carbono, devido ao seu forte caráter ácido. ${ }^{81,87}$ O ródio é um metal que promove rendimentos a hidrogênio próximos da relação quantitativa, entretanto, apresenta elevado custo. ${ }^{92}$

\section{Caminho de reação de reforma de etanol}

A reforma a vapor de etanol (Equação 1) é uma reação fortemente endotérmica: $\Delta \mathrm{H}^{\circ}=174 \mathrm{~kJ} / \mathrm{mol} \mathrm{e} \Delta \mathrm{G}^{\circ}=65 \mathrm{~kJ} / \mathrm{mol}$. Por isso, valores desejáveis de conversão de etanol e seletividade a hidrogênio só são obtidos em temperaturas superiores a $500{ }^{\circ} \mathrm{C}$. Os subprodutos formados, bem como suas quantidades relativas, dependem fortemente das condições reacionais, destacando-se o teor de água, a temperatura e o catalisador. ${ }^{68,70,93,94}$ Em geral, os metais de transição têm apresentado um bom nível de atividade e seletividade para a reforma a vapor do etanol, na seguinte ordem: $\mathrm{Co}>\mathrm{Ni}>\mathrm{Rh}>\mathrm{Pt}$, $\mathrm{Ru}, \mathrm{Cu} .{ }^{55,68,81,95}$

Na Tabela 2 são sumarizadas algumas reações observadas durante a reforma a vapor de etanol para diferentes catalisadores. De forma geral, muitos dos subprodutos são convertidos a hidrogênio em reações posteriores, por isso não são diretamente prejudiciais à produtividade de hidrogênio. Entretanto, a reação de metanação é acompanhada de grande consumo de hidrogênio e por isso é muito indesejável.
Tabela 2. Caminho de reação da reforma a vapor de etanol. Adaptada da ref. 68

\begin{tabular}{|c|c|}
\hline REAÇÃO & EQUAÇÃO \\
\hline Suprimento estequiométrico de vapor & $\mathrm{C}_{2} \mathrm{H}_{5} \mathrm{OH}+3 \mathrm{H}_{2} \mathrm{O} \rightarrow 2 \mathrm{CO}_{2}+6 \mathrm{H}_{2}$ \\
\hline \multirow[t]{2}{*}{ Suprimento deficiente de vapor } & $\mathrm{C}_{2} \mathrm{H}_{5} \mathrm{OH}+\mathrm{H}_{2} \mathrm{O} \rightarrow 2 \mathrm{CO}+4 \mathrm{H}_{2}$ \\
\hline & $\mathrm{C}_{2} \mathrm{H}_{5} \mathrm{OH}+2 \mathrm{H}_{2} \rightarrow 2 \mathrm{CH}_{4}+\mathrm{H}_{2} \mathrm{O}$ \\
\hline Desidrogenação & $\mathrm{C}_{2} \mathrm{H}_{5} \mathrm{OH} \rightarrow \mathrm{C}_{2} \mathrm{H}_{4} \mathrm{O}+\mathrm{H}_{2}$ \\
\hline Decomposição de acetaldeído & $\mathrm{C}_{2} \mathrm{H}_{4} \mathrm{O} \rightarrow \mathrm{CH}_{4}+\mathrm{CO}$ \\
\hline Reforma a vapor do acetaldeído & $\mathrm{C}_{2} \mathrm{H}_{4} \mathrm{O}+\mathrm{H}_{2} \mathrm{O} \rightarrow 3 \mathrm{H}_{2}+2 \mathrm{CO}$ \\
\hline Desidratação & $\mathrm{C}_{2} \mathrm{H}_{5} \mathrm{OH} \rightarrow \mathrm{C}_{2} \mathrm{H}_{4}+\mathrm{H}_{2} \mathrm{O}$ \\
\hline Formação de carbono & $\mathrm{C}_{2} \mathrm{H}_{4} \rightarrow$ formação de carbono \\
\hline Reforma a vapor do eteno & $\mathrm{C}_{2} \mathrm{H}_{4}+2 \mathrm{H}_{2} \mathrm{O} \rightarrow 4 \mathrm{H}_{2}+2 \mathrm{CO}$ \\
\hline \multirow[t]{3}{*}{ Decomposição de etanol } & $\mathrm{C}_{2} \mathrm{H}_{5} \mathrm{OH} \rightarrow \mathrm{CO}+\mathrm{CH}_{4}+\mathrm{H}_{2}$ \\
\hline & $2 \mathrm{C}_{2} \mathrm{H}_{5} \mathrm{OH} \rightarrow \mathrm{C}_{3} \mathrm{H}_{6} \mathrm{O}+\mathrm{CO}+3 \mathrm{H}_{2}$ \\
\hline & $2 \mathrm{C}_{2} \mathrm{H}_{5} \mathrm{OH} \rightarrow \mathrm{CO}_{2}+3 \mathrm{CH}_{4}$ \\
\hline \multirow[t]{2}{*}{ Metanação } & $\mathrm{CO}+3 \mathrm{H}_{2} \rightarrow \mathrm{CH}_{4}+\mathrm{H}_{2} \mathrm{O}$ \\
\hline & $\mathrm{CO}_{2}+4 \mathrm{H}_{2} \rightarrow \mathrm{CH}_{4}+2 \mathrm{H}_{2} \mathrm{O}$ \\
\hline Decomposição do metano & $\mathrm{CH}_{4} \rightarrow 2 \mathrm{H}_{2}+\mathrm{C}$ \\
\hline \multirow[t]{2}{*}{ Reforma a vapor de metano } & $\mathrm{CH}_{4}+2 \mathrm{H}_{2} \mathrm{O} \rightarrow 4 \mathrm{H}_{2}+\mathrm{CO}_{2}$ \\
\hline & $\mathrm{CH}_{4}+\mathrm{H}_{2} \mathrm{O} \rightarrow 3 \mathrm{H}_{2}+\mathrm{CO}$ \\
\hline Reação de Boudouard & $2 \mathrm{CO} \rightarrow \mathrm{C}(\mathrm{s})+\mathrm{CO}_{2}$ \\
\hline Water gas shift reaction (WGSR) & $\mathrm{CO}+\mathrm{H}_{2} \mathrm{O} \rightarrow \mathrm{CO}_{2}+\mathrm{H}_{2}$ \\
\hline
\end{tabular}

\section{Reforma interna direta do etanol}

Na SOFC com reforma direta de etanol, o mesmo (etanol/água ou etanol puro) é alimentado diretamente no anodo da célula. Neste tipo de SOFCs, o anodo (eletrocatalisador) converte o etanol diretamente em hidrogênio, $\mathrm{CO}_{2}$ e outros subprodutos. Os subprodutos podem ser purgados, podem ser usados para realimentar a célula ou podem ser reaproveitados para outros fins comerciais, dependendo da sua composição. ${ }^{41}$

Ainda não há entendimento preciso sobre a reação do hidrogênio 
decorrente da reforma do etanol no anodo, particularmente na SOFC com reforma direta. ${ }^{64} \mathrm{O}$ anodo pode converter o etanol a hidrogênio e, em uma reação posterior, o hidrogênio é oxidado a $\mathrm{H}^{+}$(Equações 5 e 6). Alternativamente, o anodo também pode converter diretamente os átomos de hidrogênio presentes na molécula de etanol em $\mathrm{H}^{+}$ (Equação 7):

$$
\begin{gathered}
\mathrm{C}_{2} \mathrm{H}_{5} \mathrm{OH}+3 \mathrm{H}_{2} \mathrm{O} \rightarrow 2 \mathrm{CO}_{2}+6 \mathrm{H}_{2} \\
6 \mathrm{H}_{2} \rightarrow 12 \mathrm{H}^{+}+12 \mathrm{e}^{-} \\
\mathrm{C}_{2} \mathrm{H}_{5} \mathrm{OH}+3 \mathrm{H}_{2} \mathrm{O} \rightarrow 2 \mathrm{CO}_{2}+12 \mathrm{H}^{+}+12 \mathrm{e}^{-}
\end{gathered}
$$

As SOFCs alimentadas diretamente com etanol têm a vantagem de serem mais simples e menos custosas, em relação às células com reforma externa, principalmente por não demandarem produção e purificação de hidrogênio em outras unidades. Entretanto, esse tipo de configuração apresenta grandes problemas quanto à formação de carbono. ${ }^{96}$ Isto ocorre principalmente porque níquel é o metal mais usado nos anodos e é um forte indutor da reação de formação de carbono. ${ }^{97}$ A regeneração do anodo pode ser feita por meio de oxigênio ou vapor de água, alimentados à célula degradada; embora, não haja garantias de uma boa eficiência de regeneração. Estas maneiras de regeneração do anodo podem promover a oxidação da sua fase metálica. Esta reação pode causar dilatações térmicas e trincamentos na célula; este efeito é principalmente sério na interface anodo-eletrólito, podendo comprometer o transporte de portadores de cargas: $\mathrm{H}^{+}$, na região do anodo e $\mathrm{O}^{2-}$, na região de interface anodo-eletrólito. Adicionalmente, durante a regeneração do anodo, a fase metálica pode apresentar forte sinterização, com consequente redução da atividade catalítica. ${ }^{48}$

As células alimentadas diretamente com etanol apresentam diferenças significativas em relação às células alimentadas diretamente com hidrocarbonetos, como metano e gás natural. A reação de reforma a vapor do etanol atinge conversões elevadas em temperaturas entre 500 e $800{ }^{\circ} \mathrm{C}$, permitindo que a célula seja operada com alta eficiência neste intervalo de temperatura, dando viabilidade às IT-SOFC (SOFC que operam em temperaturas intermediárias, isto é, entre 500 a $800^{\circ} \mathrm{C}$ ). Esta redução na temperatura de operação minimiza parte dos problemas causados por dilatação térmica dos componentes da célula; entretanto, demandará o desenvolvimento de eletrólitos e catodos mais ativos nesta faixa de temperatura. ${ }^{27}$ Entre os eletrólitos com elevada condutividade entre 700 e $800{ }^{\circ} \mathrm{C}$, podem-se usar os já conhecidos materiais à base de óxido de bismuto, ${ }^{18,98} \mathrm{La}_{0,9} \mathrm{Sr}_{0,1} \mathrm{Ga}_{0,8} \mathrm{Mg}_{0,2} \mathrm{O}_{3-\delta}$, $\mathrm{Gd}_{1,8} 6 \mathrm{Ca}_{0,14} \mathrm{Ti}_{2} \mathrm{O}_{7-\delta}, \mathrm{La}_{0,9} \mathrm{Sr}_{0,1} \mathrm{AlO}_{3-\delta}$, cuja condutividade chega a atingir $2 \mathrm{mS} / \mathrm{cm},{ }^{99} \mathrm{em}$ vez de se usar o mais tradicional YSZ $\left(\mathrm{Zr}_{0,9} \mathrm{Y}_{0,1} \mathrm{O}_{2-\delta}\right)$, que exibe condutividade aproximada de $1 \mathrm{mS} / \mathrm{cm}$ em temperaturas em torno de $1000{ }^{\circ} \mathrm{C} . .^{100,101}$

\section{Reforma interna indireta do etanol}

As SOFCs com reforma interna de etanol são dispositivos que contêm um reformador no interior da célula. Este tipo de configuração envolve desenvolvimento tecnológico comum às SOFC de reforma externa. É um tipo de configuração que favorece o aproveitamento do calor dissipado nos componentes da célula, seja calor do reformador para aquecer a célula, seja calor da célula para aquecer o reformador. É um tipo de configuração bastante apropriado para acoplamento a cogeradores..$^{102,103}$

Baily observou que a temperatura dos gases à saída de SOFC de alta temperatura, operando em torno de $1000^{\circ} \mathrm{C}$, é de cerca de $815^{\circ} \mathrm{C}$, após pré-aquecimento do ar. ${ }^{104} \mathrm{Gases}$ com estes níveis de temperaturas são capazes de produzir vapor com temperatura superior a $540{ }^{\circ} \mathrm{C}$, o que torna esta SOFC bastante adequada para um ciclo de geração a vapor. Temperaturas em torno de $300{ }^{\circ} \mathrm{C}$ já são capazes de promover conversão de etanol com seletividade a hidrogênio de até $30 \%$, sobre catalisadores à base de $\mathrm{Pt} / \mathrm{Al}_{2} \mathrm{O}_{3}$ e $\mathrm{Pt} / \mathrm{CeO}_{2} ;{ }^{105}$ o hidrogênio produzido pode ser direcionado para alimentar as células. A possibilidade de aplicar cogeradores acoplados à célula a combustível de óxido sólido transforma sua principal desvantagem, a elevada temperatura de operação, em uma vantagem técnica, pois aumenta o rendimento global do dispositivo.

\section{PANORAMA QUANTITATIVO DOS ESTUDOS SOBRE SOFC A ETANOL}

Este levantamento visou quantificar as publicações de estudos sobre SOFCs alimentadas com etanol, seja com aplicação de etanol direto na célula ou desenvolvimentos de anodos apropriados. Neste levantamento, consideraram-se artigos e patentes publicados.

Nas Figuras 4, 5 e 6 são mostrados os quantitativos de artigos e patentes publicados sobre aplicação de etanol em SOFC. Os dados

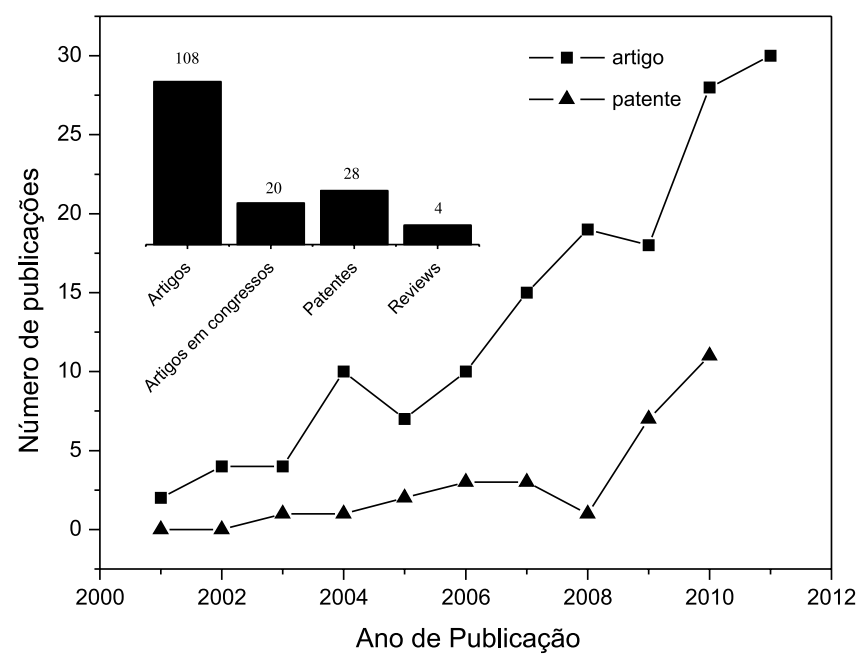

Figura 4. Evolução anual do número de publicações, divididas por categoria. Levantamento realizado em julho de 2011 no portal de periódicos da CAPES - ISI web of knowledge. Conjunto de palavras chave: ethanol and sofc*

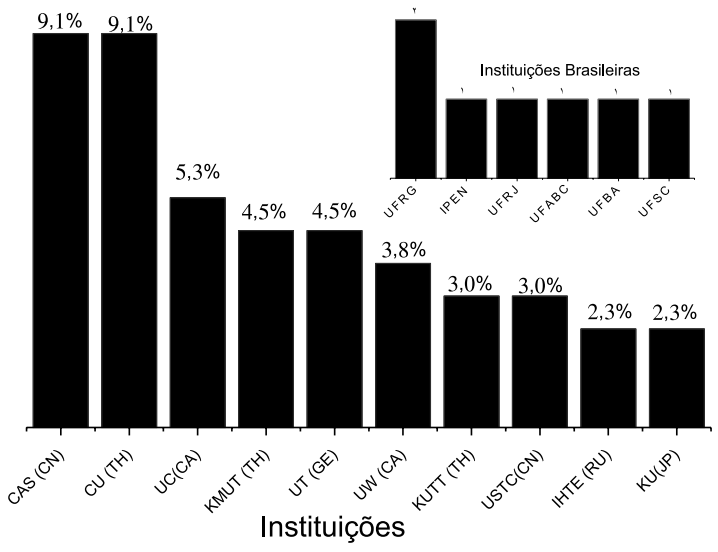

Figura 5. Relação das principais instituições internacionais (percentagem do total) e brasileiras (em números absolutos) onde se têm desenvolvido trabalhos relacionados à SOFC alimentadas com etanol. Levantamento realizado em julho de 2011 no portal de periódicos da CAPES - ISI web of knowledge. Conjunto de palavras chave: ethanol and sofc*. Chinese Acad. SCI. (CN), Chulalongkorn Univ. (TH), Univ. Calgary (CA), King Mon Univ. Technol. (TH), Univ. Thessally (GE), Univ. Waterloo (CA), King Univ. Tech. Thonburi (TH), Univ. Sci. \& technol. China (CN), Inst. High Temp. Electrochem. (RU), Kyush Univ. (JP). [CH-China, TH-Tailândia, CA-Canadá, GE-Grécia, RU-Rússia, JP-Japão] 


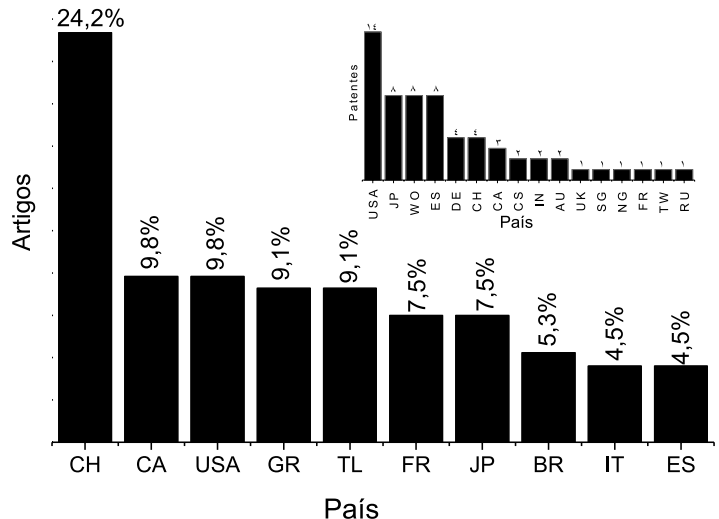

Figura 6. Relação dos principais países que têm publicado artigos e patentes relacionados com SOFC alimentadas com etanol. Levantamento realizado em julho de 2011 no portal de periódicos da CAPES - ISI web of knowledge. Conjunto de palavras chave: ethanol and sofc* [EUA-Estados Unidos, WO-Depósito Internacional de Patentes, ES-Espanha, DE-Alemanha, CS-Coreia do Sul, IN-Índia, AU-Austrália, UK-Inglaterra, SG-Singapura, NG-Noruega, FR-França, TW-Taiwan]

revelam que as publicações se iniciam, particularmente, a partir dos anos 2000. Há 152 documentos publicados, distribuídos crescentemente de 2001 a 2011, incluindo artigos, revisões, publicações em anais de eventos e patentes, os quais permeiam testes diretos com etanol em SOFC, desenvolvimento de materiais e estudos teóricos.

Dentre os 10 países que mais têm se interessado pelo desenvolvimento de pesquisa na área de SOFC alimentadas com etanol, destaca-se a China, com $24,2 \%$ de toda produção técnica. O Brasil aparece na $8^{\mathrm{a}}$ posição, porém com reais possibilidades de se destacar nos próximos anos, auxiliado pelas políticas de incentivos financeiros às pesquisas da área de energias alternativas. Estas publicações têm ocorrido em revistas especializadas, tanto nacionais como internacionais. . $8,34,41,106,107^{2}$

Quanto às patentes, que indicam apropriação de tecnologia na área, já foram publicados 29 documentos. Estados Unidos, Japão e Espanha se destacam com 14, 8 e 8 patentes cada um, respectivamente. Há também 8 depósitos internacionais pelo PCT (Tratado de Cooperação em Matéria de Patentes). Dentre os principais depositantes destacam-se empresas voltadas para a área de energia, como Fuelcell Energy INC. (USA), Inst. Nuclear Energy Res. Atomic Energy Co. (USA) e Ultracell Corp. (USA); duas importantes instituições de pesquisa, University of Pennsylvania (USA) e Forschungszentrum Jüelich GMBH (DE); e outras empresas do setor de tecnologia de materiais: Seiko Epson Corp. (JP), Hitachi Metals Ltd. (JP) e Delphi Technologies Inc. (USA).

Em relação à posição do Brasil nas publicações nacionais, em revistas indexadas, relacionadas ao desenvolvimento de SOFC alimentadas a etanol, as mesmas respondem por 5,3\% do total e estão concentradas principalmente em autores das regiões Sul e Sudeste e do estado da Bahia.

Observa-se a forte presença de centro de pesquisas da Tailândia, que está entre aqueles países que fazem investimentos elevados em pesquisa e desenvolvimento na área de SOFCs a etanol. Esta posição da Tailândia é explicada pelo fato de ser um grande produtor de etanol, tendo 40 usinas em atividade e já fazendo uso de $10 \%$ de etanol adicionado à gasolina para uso veicular. $\mathrm{O}$ país tem planos para investir em tecnologia para otimizar a produção e diversificar o uso do combustível, principalmente na área de geração de energia. ${ }^{108}$

$\mathrm{Na}$ área de SOFC alimentadas a etanol, o número de documentos publicados ainda é bastante modesto para uma tecnologia motivada por elevado rendimento da conversão de energia e um forte apelo ambiental. O reduzido número de publicações mostra que ainda há um grande espaço para investimento no desenvolvimento de tecnologias, buscando sua viabilização técnica e comercial. O campo de desenvolvimento de SOFCs alimentadas com etanol é uma boa oportunidade para investimento em formação de recursos humanos e investimentos empresariais.

\section{CONCLUSÕES E PERSPECTIVAS}

As SOFCs alimentadas a etanol têm viabilidade técnica, comprovada por avaliações teóricas e ratificada por estudos experimentais. É um importante dispositivo para a geração limpa de energia podendo, a médio ou longo prazo, complementar a matriz energética mundial e, principalmente, a matriz brasileira. Os resultados experimentais já indicam que células alimentadas com etanol podem atingir densidade de potência em torno de $450 \mathrm{~mW} / \mathrm{cm}^{2}$, número similar às células alimentadas com hidrogênio; portanto, encorajando o scale up de células alimentadas com etanol para unidades maiores, com capacidades entre 5 e $200 \mathrm{~kW}$. Os estudos em SOFCs com reforma direta ou interna de etanol estão avançando de forma singular, criando expectativas positivas e recursos humanos qualificados para alcançar um estágio de desenvolvimento tecnológico capaz de gerar viabilidade comercial.

Embora o cenário seja de otimismo quanto à viabilização de um dispositivo eficiente e de baixa emissão de poluentes na geração de energia, ainda há grandes desafios tecnológicos, principalmente visando minimizar a produção de carbono pelos materiais (eletrocatalisadores) usados para transformar etanol em hidrogênio, seja diretamente na célula ou em reformador externo ou interno à célula.

Os elevados investimentos mundiais, públicos e privados, e os atraentes aspectos ambientais da tecnologia sugerem que as SOFCs deverão atingir, a médio ou longo prazo, um alto grau de desenvolvimento. Isto permitirá a inserção das SOFC no mercado de geração de energia elétrica, sendo uma ótima alternativa para a geração descentralizada de energia.

\section{REFERÊNCIAS}

1. Balat, M.; Balat, H.; Appl. Energy 2009, 86, 2273.

2. Balat, H.; Energy Educ. Sci. Technol., A 2010, $24,85$.

3. Gonzalez-Avila, M. E.; Beltran-Morales, L. F.; Troyo-Dieguez, E.; Ortega-Rubio, A.; Interciencia 2006, 31, 240.

4. Rosa, L. P.; Campos, C. P.; Araujo, M. S. M.; J. Renewable Sustainable Energy 2009, 1, 033111.

5. Quintella, C. M.; Teixeira, L. S. G.; Korn, M. G. A.; Costa Neto, P. R.; Torres, E. A.; Castro, M. P.; Jesus, C. A. C.; Quim. Nova 2009, 32, 793.

6. Vaccaro, G. L. R.; Pohlmann, C.; Lima, A. C.; dos Santos, M. S.; de Souza, C. B.; Azevedo, D.; Renewable Sustainable Energy Rev. 2010, $14,1263$.

7. Janaun, J.; Ellis, N.; Renewable Sustainable Energy Rev. 2010, 14, 1312.

8. Pinto, A. C.; Guarieiro, L. L. N.; Rezende, M. J. C.; Ribeiro, N. M.; Torres, E. A.; Lopes, W. A.; Pereira, P. A. D.; de Andrade, J. B.; J. Braz. Chem. Soc. 2005, 16, 1313.

9. Stambuk, B. U.; Eleutherio, E. C. A.; Florez-Pardo, L. M.; Souto-Maior, A. M.; Bon, E. P. S.; J. Scientific Ind. Res. 2008, 67, 918.

10. Macedo, I. C.; Seabra, J. E. A.; Silva, J.; Biomass Bioenergy 2008, 32, 582.

11. Demirbas, A.; Appl. Energy 2009, 86, S108.

12. Migoya, E.; Crespo, A.; Jimenez, A.; Garcia, J.; Manuel, F.; Renewable Energy 2007, 32, 1467.

13. Calero, R.; Carta, J. A.; Energy Policy 2004, 32, 1185.

14. Erdal, H.; Erdal, G.; Esengun, K.; Energy Sources, B 2009, 4, 387.

15. Nogueira, L. A. H.; Bioetanol de cana-de-açúcar: Energia para o desenvolvimento sustentável, BNDES: Brasília, 2008. 
16. Liso, V.; Zhao, Y. R.; Brandon, N.; Nielsen, M. P.; Koer, S. K.; Int. J. Hydrogen Energy 2011, 36, 13715.

17. http://www.mct.gov.br/index.php/content/view/120102.html, acessada em Maio 2012

18. Atkinson, A.; Barnett, S.; Gorte, R. J.; Irvine, J. T. S.; McEvoy, A. J.; Mogensen, M.; Singhal, S. C.; Vohs, J.; Nat. Mater. 2004, 3, 17.

19. Wendt, H.; Gotz, M.; Linardi, M.; Quim. Nova 2000, 23, 538.

20. Florio, D. Z.; Varela, J. A.; Fonseca, F. C.; Muccillo, E. N. S.; Muccillo, R.; Quim. Nova 2007, 30, 1339

21. Sordi, A.; Silva, E. P.; Marin Netto, A. J.; Lopes, D. G.; Pinto, C. S.; Araujo, P. D.; Braz. J. Chem. Eng. 2009, 26, 745

22. Silva, M. A.; Boaventura, J. S.; Alencar, M. G.; Cerqueira, C. P.; Revista Matéria 2007, 12, 99.

23. Lim, K. L.; Kazemian, H.; Yaakob, Z.; Daud, W. R. W.; Chem. Eng. Technol. 2010, 33, 213.

24. Jiang, H. L.; Singh, S. K.; Yan, J. M.; Zhang, X. B.; Xu, Q.; ChemSusChem. 2010, 3, 541.

25. Hu, Y. H.; Zhang, L.; Adv. Mater. 2010, 22, E117.

26. Hotza, D.; Costa, J. C. D.; Int. J. Hydrogen Energy 2008, 33, 4915.

27. Muccillo, R.; Muccillo, E. N. S.; Fonseca, F. C.; de Florio, D. Z.; J. Electrochem. Soc. 2008, 155, B232.

28. Silva, M. A.; Alencar, M. G. F.; Fiuza, R. P.; Boaventura, J. S.; Revista Matéria 2007, 12, 13.

29. Ye, X. F.; Wang, S. R.; Hu, Q.; Chen, J. Y.; Wen, T. L.; Wen, Z. Y.; Solid State Ionics 2009, 180, 276.

30. Cimenti, M.; Hill, J. M.; Asia-Pac. J. Chem. Eng. 2009, 4, 45.

31. Arpornwichanop, A.; Chalermpanchai, N.; Patcharavorachot, Y.; Assabumrungrat, S.; Tade, M.; Int. J. Hydrogen Energy 2009, 34, 7780.

32. Cimenti, M.; Hill, J. M.; J. Power Sources 2009, 186, 377.

33. Arteaga-Perez, L. E.; Casas, Y.; Peralta, L. M.; Kafarov, V.; Dewulf, J.; Giunta, P.; Chem. Eng. J. 2009, 150, 242.

34. Fiuza, R. P.; Silva, M. A.; Boaventura, J. S.; Int. J. Hydrogen Energy 2010, 35, 11216.

35. Alberton, A. L.; Souza, M. M. V. M.; Schmal, M.; Catal. Today 2007, $123,257$.

36. Clarke, S. H.; Dicks, A. L.; Pointon, K.; Smith, T. A.; Swann, A.; Catal. Today 1997, 38, 411.

37. Qin, H. Y.; Zhu, Z. G.; Liu, Q. H.; Jing, Y. F.; Raza, R.; Imran, S.; Singh, M.; Abbas, G.; Zhu, B.; Energy Environ. Sci. 2011, 4, 1273.

38. Peters, T. A.; Kaleta, T.; Stange, M.; Bredesen, R.; J. Membr. Sci. 2011, $383,124$.

39. Yang, T. X.; Xiao, Y. C.; Chung, T. S.; Energy Environ. Sci. 2011, 4, 4171.

40. Assabumrungrat, S.; Pavarajarn, V.; Charojrochkul, S.; Laosiripojana, N.; Chem. Eng. Sci. 2004, 59, 6015.

41. Venancio, S. A.; Gutierres, T. F.; Sarruf, B. J. M.; Miranda, P. E. V.; Revista Matéria 2008, 13, 560.

42. Koh, J. H.; Yoo, Y.-S.; Park, J. W.; Lim, H. C.; Solid State Ionics 2002, $149,157$.

43. Maia, T. A.; Bellido, J. D. A.; Assaf, E. M.; Assaf, J. M.; Quim. Nova 2007, 30, 339

44. Profeti, L. P. R.; Dias, J. A. C.; Assaf, J. M.; Assaf, E. M.; J. Power Sources 2009, 190, 525.

45. Lima, S. M.; Silva, M. A.; Costa, L. O. O.; Assaf, J. M.; Jacobs, G.; Davis, B. H.; Mattos, L. V.; Noronha, F. B.; Appl. Catal., A 2010, 377, 181.

46. Bshish, A.; Yakoob, Z.; Narayanan, B.; Ramakrishnan, R.; Ebshish, A.; Chem. Pap. 2011, 65, 251.

47. Soares, A. B.; Silva, P. R. N.; Freitas, J. C. C.; Almeida, C. M.; Quim. Nova 2007, 30, 1061 .

48. Chen, S. I.; Li, Y. D.; Liu, Y.; Bai, X.; Int. J. Hydrogen Energy 2011, 36, 5849 .

49. Silva, A. M.; Souza, K. R.; Mattos, L. V.; Jacobs, G.; Davis, B. H.; Noronha, F. B.; Catal. Today 2011, 164, 234.
50. Profeti, L. P. R.; Ticianelli, E. A.; Assaf, E. M.; Appl. Catal., A 2009, $360,17$.

51. Silva, A. M.; Souza, K. R.; Jacobs, G.; Graham, U. M.; Davis, B. H.; Mattos, L. V.; Noronha, F. B.; Appl. Catal., B 2011, 102, 94.

52. Cerritos, R. C.; Ramirez, R. F.; Alvarado, A. F.A.; Rosales, J. M. M.; Garcia, T. V.; Galindo, I. R. G.; Ind. Eng. Chem. Res. 2011, 50, 2576.

53. Fiuza, R. P.; Boaventura, J. S.; Oliveira, M. 1.; Silva, M. A.; Guedes, B. C.; Carvalho, L. F.; Resumos do $18^{\circ}$ CBCIMAT- Congresso Brasileiro de Engenharia e Ciência dos Materiais, Porto de Galinhas, Brasil, 2008.

54. Lee, J. Y.; Lee, D.-W.; Hong, Y.-K.; Lee, K.-Y.; Int. J. Hydrogen Energy 2011, 36, 8173 .

55. Haryanto, A.; Fernando, S.; Murali, N.; Adhikari, S.; Energy Fuels 2005, 19, 2098

56. Singhal, S. C.; Solid State Ionics 2002, 152, 405

57. Santin, M.; Traverso, A.; Magistri, L.; Massardo, A.; Energy 2010, 35, 1077.

58. Chiappini, D.; Facci, A. L.; Tribioli, L.; Ubertini, S.; J. Fuel Cell Sci. Technol. 2011, 8, 031015.

59. Serra, E.; Furtado, J. G.; Soares, G.; Codeceira Neto, A.; Células a Combustível: Uma alternativa para a geração de energia e sua inserção no mercado Brasileiro. Centro de Pesquisas de Energia Elétrica (CEPEL): Rio de Janeiro, 2005.

60. Tsiakaras, P.; Demin, A.; J. Power Sources 2001, 102, 210.

61. Mogensen, D.; Grunwaldt, J. D.; Hendriksen, P. V.; Dam-Johansen, K.; Nielsen, J. U.; J. Power Sources 2011, 196, 25.

62. Fiuza, R. P.; Boaventura, J. S.; Barreto, E. G.; Silva, M. A.; Guedes, B. C.; Carvalho, L. F.; Fiuza, R. A.; Univ. Fed. Bahia, Br PI 11.100.000.6952010.

63. Fiuza, R. P.; Silva, M. A.; Boaventura, J. S.; Univ. Fed. Bahia, Br PI 11.100.000.6962010.

64. Cimenti, M.; Hill, J. M.; J. Power Sources 2010, 195, 3996.

65. Lanzini, A.; Santarelli, M.; Orsello, G.; Fuel Cells 2010, 10, 654.

66. Wang, K.; Hissel, D.; Pera, M. C.; Steiner, N.; Marra, D.; Sorrentino, M.; Pianese, C.; Monteverde, M.; Cardone, P.; Saarinen, J.; Inter. J. Hydrogen Energy 2011, 36, 7212.

67. Cowin, P. I.; Petit, C. T. G.; Lan, R.; Irvine, J. T. S.; Tao, S. W.; Adv. Energy Mater. 2011, 1, 314.

68. Ni, M.; Leung, D. Y. C.; Leung, M. K. H.; Int. J. Hydrogen Energy 2007, 32,3238 .

69. Ni, M.; Leung, M. K. H.; Leung, D. C.; Int. J. Hydrogen Energy 2007, 32,4648 .

70. Vizcaino, A. J.; Carriero, A.; Calles, J. A.; Int. J. Hydrogen Energy 2007, 32,1450 .

71. Bichon, P.; Haugom, G.; Venvik, H. J.; Holmen, A.; Blekkan, E. A.; Top. Catal. 2008, 49, 38.

72. Song, H.; Tan, B.; Ozkan, U. S.; Catal. Lett. 2009, 132, 422.

73. Santos, R. K. S.; Batista, M. S.; Assaf, E. M.; Assaf, J. M.; Quim. Nova 2005, $28,587$.

74. Liguras, D. K.; Kondarides, D. I.; Verykios, X. E.; Appl. Catal., B 2003, 43, 345 .

75. Petkovic, L. M.; Rashkeev, S. N.; Ginosar, D. M.; Catal. Today 2009, 147, 107.

76. Koh, A. C. W.; Chen, L. W.; Leong, W. K.; Ang, T. P.; Johnson, B. F. G.; Khimyak, T.; Lin, J. Y.; Int. J. Hydrogen Energy 2009, 34, 5691.

77. Camargo, A. P. M.; Previdello, B. A. F.; Varela, H.; Gonzalez, E. R.; Quim. Nova 2010, 33, 2143.

78. Martins, R. F.; Brant, M. C.; Domingues, R. Z.; Paniago, R. M.; Sapag, K.; Matencio, T.; Mater. Res. Bull. 2009, 44, 451.

79. Rostrup-Nielsen, J. R.; Sehested, J.; Norskov, J. K.; Adv. Catal. 2002, 47,65 .

80. Fatsikostas, A. N.; Verykios, X. E.; J. Catal. 2004, 225, 439.

81. Comas, J.; Mariño, F.; Laborde, M.; Amadeo, N.; Chem. Eng. J. 2004 98, 61 . 
82. Comas, J.; Dieuzeide, M. L.; Baronetti, G.; Laborde, M.; Amadeo, N.; Chem. Eng. J. 2006, 118, 11.

83. Sahoo, D. R.; Vajpai, S.; Patel, S.; Pant, K. K.; Chem. Eng. J. 2007, 125, 139.

84. Verónica, M.; Graciela, B.; Norma, A.; Miguel, L.; Chem. Eng. J. 2008 $138,602$.

85. Lima, S. M.; Silva, A. M.; Cruz, I. O.; Jacobs, G.; Davis, B. H.; Mattos, L. V.; Noronha, F. B.; Catal. Today 2008, 138, 162.

86. Vaidya, P. D.; Rodrigues, A. E.; Chem. Eng. J. 2006, 117, 39.

87. Marino, F.; Baronetti, G.; Jobbagy, M.; Laborde, M.; Appl. Catal., A 2003, 238, 41 .

88. Vizcaino, A. J.; Arena, P.; Baronetti, G.; Carrero, A.; Calles, J. A.; Laborde, M. A.; Amadeo, N.; Int. J. Hydrogen Energy 2008, 33, 3489.

89. Resini, C.; Cavallaro, S.; Frusteri, F.; Freni, S.; Busca, G.; React. Kinet Catal. Lett. 2007, 90, 117

90. Deng, X. Z.; Sun, J.; Yu, S. S.; Xi, J. Y.; Zhu, W. T.; Qiu, X. P.; Int. J. Hydrogen Energy 2008, 33, 1008.

91. Gavrielatos, I.; Drakopoulos, V.; Neophytides, S. G.; J. Catal. 2008, 259 75.

92. Cavallaro, S.; Chiodo, V.; Freni, S.; Mondello, N.; Frusteri, F.; Appl. Catal., A 2003, 249, 119.

93. Resini, C.; Montanari, T.; Barattini, L.; Ramis, G.; Busca, G.; Presto, S.; Riani, P.; Marazza, R.; Sisani, M.; Marmottini, F.; Costantino, U.; Appl. Catal., A 2009, 355, 83.
94. Laosiripojana, N.; Assabumrungrat, S.; J. Power Sources 2007, 163, 943. 95. Bellido, J. D. A.; Assaf, E. M.; J. Power Sources 2008, 177, 24.

96. Huang, B.; Wang, S. R.; Liu, R. Z.; Wen, T. L.; J. Power Sources 2007, 167, 288.

97. Jiang, S. P.; Chan, S. H.; J. Mater. Sci. 2004, 39, 4405.

98. Singhal, S. C.; Solid State Ionics 2000, 135, 305.

99. Tsipis, E. V.; Kharton, V. V., J. Solid State Electrochem. 2008, 12, 1367.

100. Chockalingam, R.; Amarakoon, V. R. W.; Giesche, H.; J. Eur. Ceram. Soc. 2008, 28, 959.

101. Haile, S. M.; Acta Mater. 2003, 51, 5981.

102. Velumani, S.; Guzman, C. E.; Peniche, R.; Vega, R.; Int. J. Energy Res. 2010, 34, 1088

103. Wakui, T.; Yokoyama, R.; J. Fuel Cell Sci. Technol. 2011, 8, 041011.

104. Baily, F. G.; Resumos do 35 th GE Turbine State-of-art Tecnology Seminar, Munique, Alemanha, 1991.

105. Ciambelli, P.; Palma, V.; Ruggiero, A.; Appl. Catal., B 2010, 96, 18.

106. Taroco, H. A.; Andrade, S. T. D.; Brant, M. C.; Domingues, R. Z.; Matencio, T.; Quim. Nova 2009, 32, 1297.

107. Hotza, D.; Revista Matéria 2009, 14, 1101

108. Nguyen, T. L. T.; Gheewala, S. H.; Garivait, S.; Appl. Energy 2008, 85, 722 . 